\title{
Accurate On-line Intervention Practices for Efficient Improvement of Reading Skills in Africa
}

\author{
Minda B Marshall \\ LectorSA Mokopane, South Africa
}

Copyright $(2016$ by authors, all rights reserved. Authors agree that this article remains permanently open access under the terms of the Creative Commons Attribution License 4.0 international License.

\begin{abstract}
Lifelong learning is the only way to sustain proficient learning in a rapidly changing world. Knowledge and information are exploding across the globe. We need accurate ways to facilitate the process of drawing external factual information into an internal perceptive advantage from which to interpret and argue new information. Accurate and Effective Reading enables us to act creatively and critically in a world which is ever-changing. It provides rapid, ready access to new information and knowledge that will promote lifelong learning. LAB-on-line, a South African initiative, has proven that reading skills development is possible through visual skills and silent reading fluency improvement combined with upgrading of comprehension strategies. LAB has assisted more than 38 000 users, from Grade 1 to tertiary students to read faster, read better and remember more. [1]This project looked at the 2014/15 LAB-on-line results in a case study of students from various public and private schools (Grade 1 to Grade 12) across South Africa. LectorSA developed LAB-on-line based on 30 years of research as an on-line student interface to assist students from Grade 1 through tertiary student levels in developing the crucial skills needed to access information intelligently.[2]
\end{abstract}

Keywords Bridging the Gap in Reading Skills, Improved Academic Outcomes, Visual Skills Development, Comprehension Skills and Strategies, On-line Teacher and Student Support and Monitoring

\section{Introduction}

Illiteracy is one of the leading causes of delinquency, poverty, frustration and depression which lead to a loss in productivity and general reduction in lifestyles and wellness amongst people in all global communities. The current economic situation has made this phenomenon even worse. High-performance environments (work, learning and sport) are here to stay and people require effective solutions which will give them the opportunity to overcome in life and to contribute by creating a healthy society. These statements confirm that the need to accurately bridge this gap with effective, targeted intervention is not merely an option, but becoming essential.

There are currently wide discussions concerning the fact that governments across the world are spending billions on improving curricula and creating cutting edge environments in an effort to improve academic achievement. Nevertheless, students are still struggling to keep up with their studies. There is a gap that is increasing each year, between students and the information they have to study. It is a well described fact in research that the low levels of learners and students' reading skills play a pivotal role in academic results.[3]

The second gap that needs attention is the current situation regarding the inefficiency of South African teachers to teach reading to their students. The NRS[4] (South African Department of Basic education - National reading Strategy) recognizes that many teachers do not know how to teach reading and therefore listed teacher training, development and support as a key pillar of the NRS (DoE, 2008).[5] There are various reasons that the reading problem in South Africa is not effectively addressed, to mention a few:

- Inadequate teacher training and monitoring (Howie et al. 2006; NRS 2008)[6],

- the misconception that the low literacy levels are a direct result of the poor language proficiency of students without any recognition of the importance of reading,

- the reading problem in South Africa tends to be masked by the language problems (Pretorius, 2002:174)[7]

- teachers attribute the difficulties that students experience in reading comprehension to limited language proficiency, the underlying assumption being that language proficiency and reading ability are 'the same thing'.

The challenge before us is vast, but there are proven, 
efficient intervention systems available that are effective in today's fast growing internet environment. Combining years of research in intervention and development strategies with cutting edge technology available through the internet has made reading skills proficiency a possibility to $99 \%$ of our students. The development in technology and specifically internet connectivity makes new and effective ways of addressing and monitoring old challenges possible.

Reading is recognized as the foundation of all learning. Louden et al. (2000) states that $80 \%$ of all learning difficulties can be ascribed to poor reading skills. According to their studies poor reading skills do not only have a great negative impact on academic achievement but also on emotional development, which in turn leads to poor life skills development, misconduct, not achieving academic potential and inability to pursue a meaningful career, unless attention is devoted timely to these challenges and issues.[8] Koenig et al. indicates that reading proficiency is one of the most important predictors of academic achievement in higher education and cannot be left to random accomplishment. As some students terminate their studies due to a lack of reading proficiency, reading development programmes should be high on the priority list of scaffolding processes aimed at first-year students.[9]

LAB-on-line[10] an on-line system created by LectorSA, began as a quest to understand and enhance the measurable aspects of interaction between the eyes and the brain. By exercising the eyes and training the brain we can increase the activity in the brain, which plays a central role in mental health and ability. LAB-on-line claims to bridge the gap between the student and the curriculum by developing:

- Visual Skills

- Perceptual Skills

- Vocabulary

- Language

- Comprehension Skills

- $\quad$ Reading Strategies

- $\quad$ Study Strategies and Skills

The system claims that by training and increasing eye-brain performance we can produce healthier, stronger minds.

\section{Spectrum of Readers in South African Classrooms}

\section{Evaluation}

In February 2011, the Annual National Assessment[11] (ANA) was written by all learners in public schools in Grades 2 to 7. The South African Department of Basic Education (DBE) (2011:6) reveals that "The percentage of learners reaching at least a 'partially achieved' level of performance varies from $30 \%$ to $47 \%$, depending on the grade and subject considered. The percentage of learners reaching the 'achieved' level of performance varies from $12 \%$ to $31 \% "$ ".[12]

LectorSA[13] evaluations across South Africa indicates that the average skill level in silent fluency reading evaluated in learners from different segments of the education market is at a Grade 3 norm relative efficiency level. $11 \%$ of students in the normal classroom have reading problems, and can be referred to as accurately diagnosed with dyslexia, perceptual sensitivity syndrome and more. $76 \%$ of students in the normal classroom are students that can be referred to as poor readers, because of various factors, and $13 \%$ of students can be referred to as good readers, students that do not yet achieve the maximum potential and can still improve their reading skills.

Our brains are naturally wired for oral language development, but reading skills have to be trained in every phase and area of life development.[14] Reading development is not completed at the end of Primary School years. Even up to the end of the final year of schooling and beyond training in reading skills is important in developing the full potential of learners.

In-house research indicates that the biggest challenges in accurate and timely development of reading skills is

- Optic-motor skills

- Visual skills

- Language skills and

- Comprehension skill development

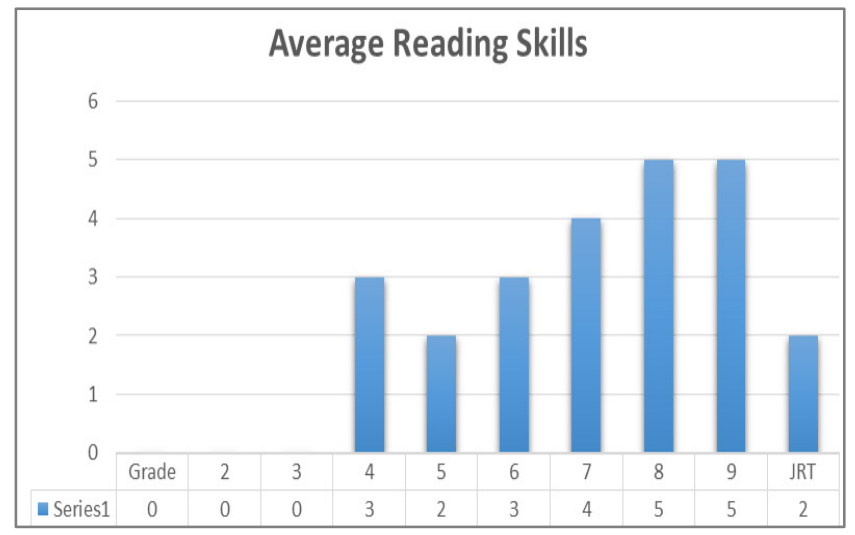

Figure 1. Graph of LectorSA evaluations 2013-2015

Aside from these basic skills needed to ensure a proficient reading ability, the student walks into the classroom with his/her very personal background and skill set. Home, community, school, culture, and individual characteristics all shape the life experiences that readers bring to reading. They help form the complex persona of the reader that forms the basis for understanding the reading process. The background information readers bring to a text - including the knowledge of habits and beliefs from their own life experiences - is often referred to as schema. What people already know about the history, culture, habits, politics, sports, and music of any given place helps them to understand when reading about it. Also, the way they learned to read as well as the reading and comprehension strategies they have learned to master, affects their degree 
of success in understanding a particularly difficult text. We are faced with a variety of these challenges and scenarios every day in the classrooms.

The current evaluations on reading skills according to ANAS outcomes also indicates the challenge in reading and development of this important skill on another level.[15] Areas of weakness in the 2012 results are indicated as:

- Knowledge of grammar is very limited

- Comprehension is poor

- $\quad$ Students struggle to give meaningful written outputs

- Students have a lack of ability to infer

- $\quad$ Frequently used words are spelled incorrectly

- Students cannot follow a sequence of events

- Students have an inability to read with understanding

- Knowledge and skills are not appropriate to the grade level mastered

We believe there are various factors that are currently playing a role in the poor outcomes in reading and comprehension skills development in South African schools:

- The most important factor is the lack of preparation of teachers during their training years in understanding what reading is, how important the development of this skill is and how it is taught, monitored, intervened and developed throughout the 12 years of primary and secondary school. Teachers do not understand that oral language and written language call on different skills. Research by Hacquebord (1994)[16] has shown that improving language proficiency does not readily improve reading comprehension. Rather, it is attention to reading that improves reading skill, during which language proficiency also improves (Elley, 1991; [17]. Mbise, 1993[18]) This situation give rise to much concern given that reading is fundamental to the learning process.

- The second is the lack of opportunity in the curriculum from Grade 1 through Grade 12 in instruction and development of the three important skill areas of reading: optic-motor, perceptual and cognitive, including reading and comprehension strategies.

- The third is a lack of understanding in the public concerning the importance of training in reading skills and a focus on other less important skills at inappropriate times in the curriculum.

- $\quad$ Fourthly holding on the false ideas i.e. that reading can only the improved in the first few years of schooling, and that students cannot make use of on-line systems to improve their skills and learn new strategies for improved reading and comprehension outcomes.

- Lastly the belief that reading skills does not influence academic outcomes and also the structuring of life-long learning in our students, adds up to an unwillingness to engage in developing these skills.

The National Reading Panel report (2000)[19] in the USA documents the relationship of eye movement recording to fluency or efficiency in silent reading. Further, the NRP report cites the norm study by Taylor, Frackenpohl, and Pettee (1960), which involved a study of the oculomotor performance of more than 12,000 students at all grade levels. Figure 2 contains the expected norms and standards for silent reading fluency with a comprehension proficiency of $70 \%$ that was adapted and implemented from the norm study referred to below.

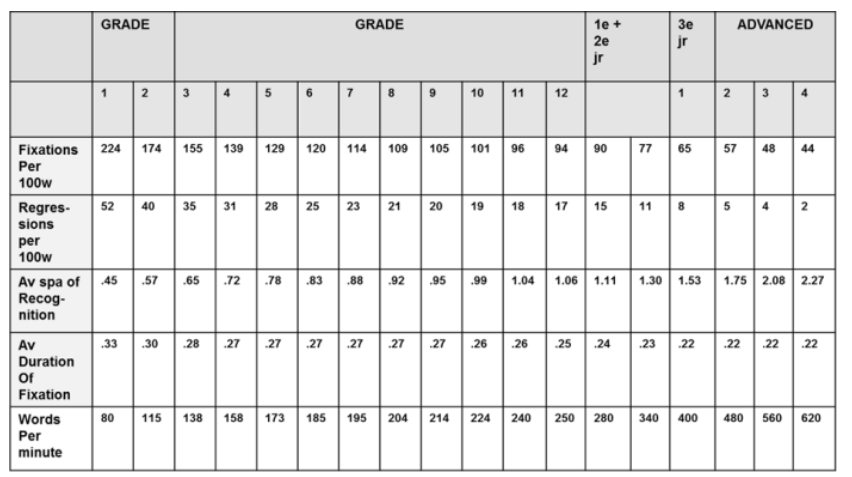

Figure 2. Expected norms and standards

See expected outcomes in Addendum A

\section{LAB-on-line Method [20]}

Lab-on-line was developed as a cloud-hosted solution in order to create a sustainable interactive process that is monitored for teacher support. This system enables 30 years of research and practical implementation to meet cutting edge technology so that student progress and teacher support can be monitored.

\section{Components in the system}

The system includes an eye-gym for visual skills development. Improvement of reading skills and strategies is gauged through on-line, down-loadable and add-on materials that is focused on comprehension skills and strategy development. Lab-on-line has a personal student profile that is connected to a Client based Learner Management and monitoring System. Results from profiles can be utilised diagnostically to ensure accurate changes to curriculum and support programs.

\section{Evaluation}

Results have proven a blended learning approach as the best. Students are:

- Evaluated according to the LAB-on-line prescribed paper based evaluations and briefed[21]

- $\quad$ assisted with the on-line evaluation

- assisted during Lesson 1 and then continues 
according to the school Implementation Plan with Lesson 2 through 20

- $\quad$ assisted with the Final Evaluations process.

\section{Cloud Based Monitored Intervention}

The LAB-on-line Solution is CLOUD-based and as a result can be applied in most on-line environments. Users can log-on anytime, anywhere and continue with reading skills development on PC, laptop, tablet, and smartphones. LAB-on-line is maximised for GOOGLE Chrome, and has been proven to raise reading levels, increase cognition, improve IQ, and develop better language skills and learning abilities for its users within 20 lessons. Lab is developed:

- $\quad$ as an interactive automated process - requiring low to no supervision

- to include Pre- and Post- Evaluations

- to include real time online reporting

- to consist of 20 automated lessons compiled into a reading course

- for lessons to be completed any time anywhere - as long as you have an internet connection on pc, laptop, tablet and/or smartphone.

\section{Key-features and benefits of LAB-on-line [22]}

- Cloud Solution that enables on-line access, is suitable for all levels, operates on most devices

- Eye-brain gym that develops visual skills, memory, improves vocabulary and assist students to see faster and remember more

- A virtual reading lab that is automated and requires little supervision it is self-paced and individualised and the diagnostic interpretation of results

- The system is continually improved through changes according to researched outcomes

- Lab-on-line assists students in neuro-wiring by training in structured access to information and developing skills and strategies to read and evaluate information critically

\section{LAB-on-line Monitoring, Support and Reporting}

A Professional Management and Reporting System ensures accurate implementation and optimal results as students are mentored on-line.

Monitoring of profiles through an interactive support structure with feedback to on-site facilitators has proven effective. Students can be reached via e-mail to assist the moment outcomes are reported to be outside best practise parameters.

Real-time measurable results are available for the student and administrator at the click of a button referencing individual and group reporting.

A Profile Manager monitors the implementation and progress of the project for optimal results. This makes implementation in large numbers a viable option.

\section{Results}

Pre- and post-evaluations on the Visagraph eye tracking evaluation system was done to use as a reference for Lab-online placements and results.

Refer to Figure 3 below for Pre Lab-on-line outcomes and Post Lab-on-line outcomes of Visagraph results.

Results were taken from a random group of 15 students from Grade $4-8$ reading at a Support center in Mokopane, Limpopo Province.

Fixations for the group decreased from 236 to 130 after 20 lessons on Lab-on-line. Regressions decreased from 66 to 17 and the Average Span of Recognition improved from 0,59 to 6,7 . The Average Duration of Fixation was much faster at 0,29 of a second from 0,96 of a second.

Words per Minute increased from 127 to 184 and even though the comprehension was $4 \%$ lower at the final evaluation the increase in relative reading efficiency as measured in Grade Level outcomes improved with 3 years within the three months the students were working on the Lab-on-line system.

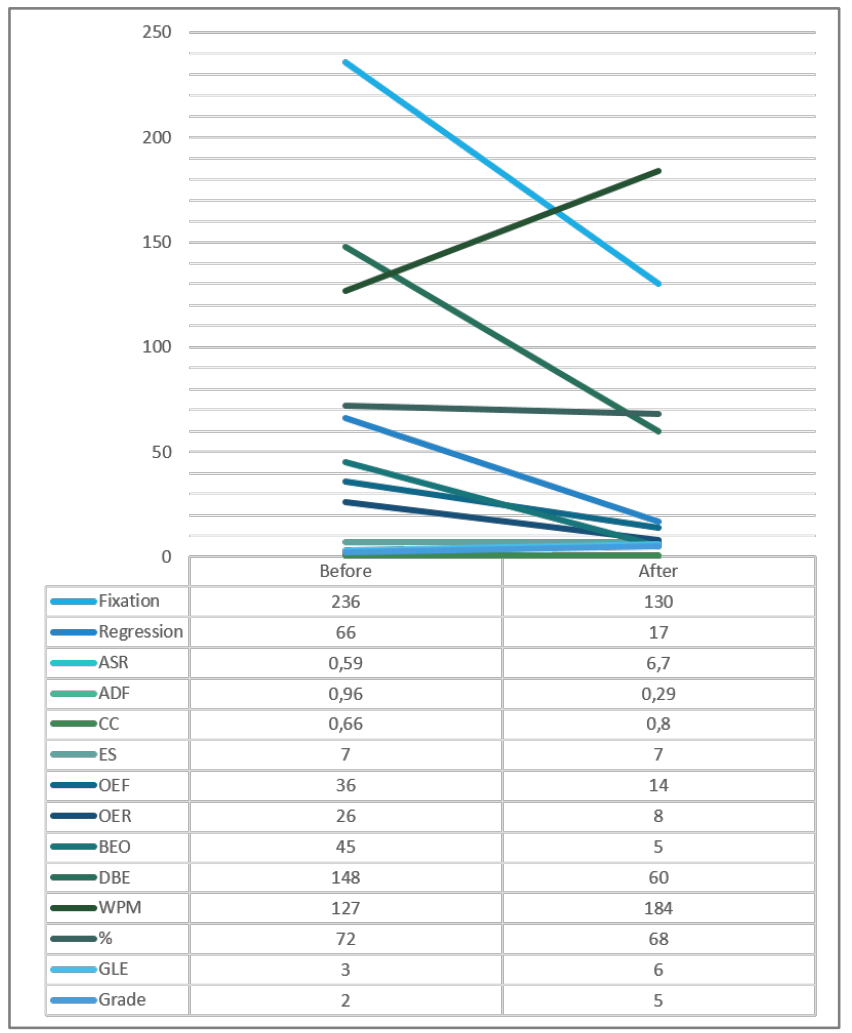

Figure 3. Results on Visagraph evaluations[23]

The Visagraph evaluation indicates a $72 \%$ Average Improvement on Measurable Aspects in reading skills of these students. 


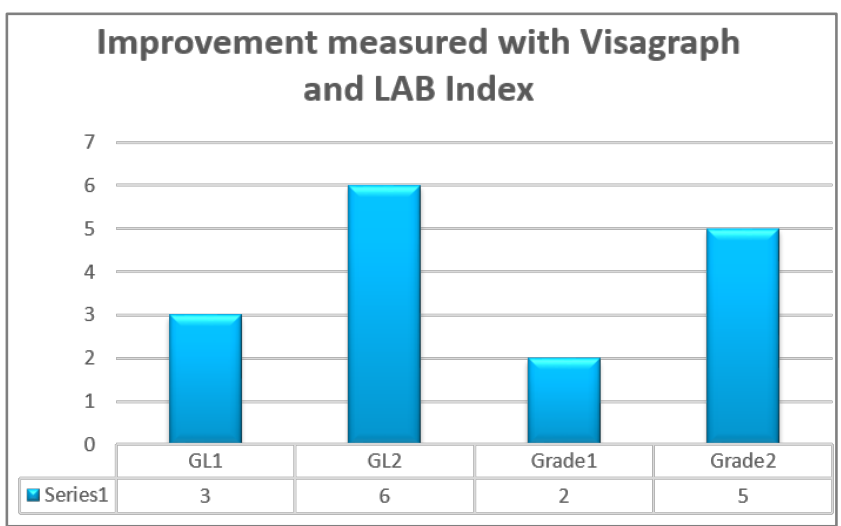

Figure 4. Correlation of results from Visagraph and Lab-on-line System [24]

Results show a correlation of 3 Years Relative Improvement (2013/14) on reading skills in both the Visagraph and Lab-on-line evaluations.

Improvement rates were measured in reading speed (measured as words per minute), comprehension and Efficiency (measured as a Grade Level). [25] In referencing the Lab-on-line results to the Visagraph results there is a correlation of three years' relative improvement of reading skills in the pre-and post- evaluation in both the evaluation.

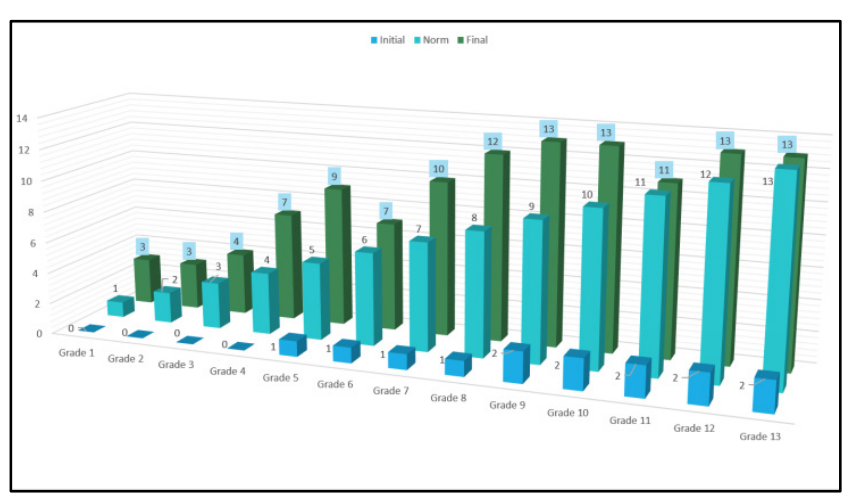

Figure 5. Final results of students on LAB-on-line 2014

See final results in Addendum B

\section{Academic Impact}

Improved Reading skills are proven to have a direct impact on Academic Achievement. At a Rustenburg School 133 Grade 12 learners participated. They were targeted for the project because they were distinction candidates for the final exam and needed assistance to ensure best outcomes in their exam. Their Academic average improved from $74 \%$ $81 \%$.

- Reading speed: 80 wpm improvement

- Comprehension: $30 \%$ improvement

- Relative Reading Efficiency: 5 years' improvement

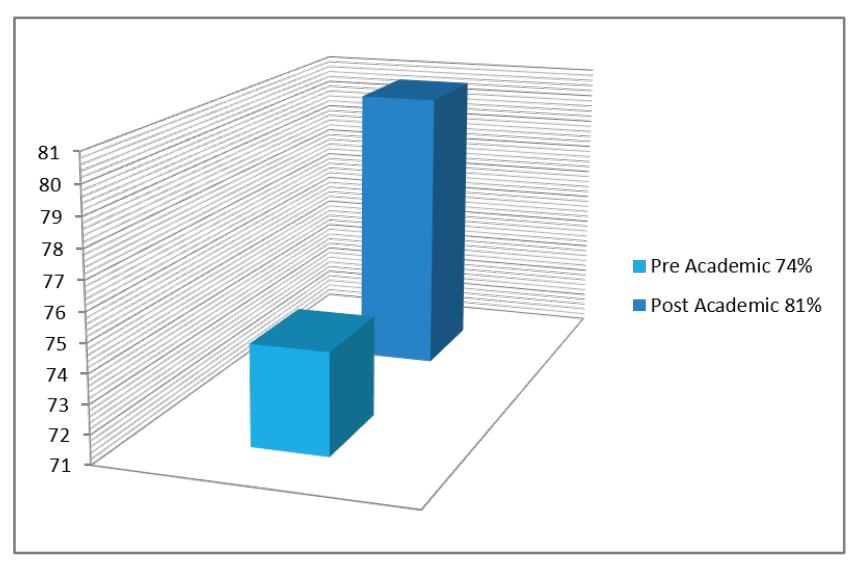

Figure 6. Academic Improvement as average \% of results[26]

\section{Discussion}

Reading is, without a doubt, the most important linguistic skill that needs to be developed. Reading serves as a building block upon which all other learning takes place. By developing reading, we will be giving our students one of the greatest gifts of life, namely, life-long learning.[27]

Fig. 1 shows the current state of reading skills of students in South Africa. These outcomes are reflected in various evaluations on reading skills development done by the DBE through the ANAS evaluations, as well as other evaluations done by the government and other private institutions.

Fig. 2 indicates the expected outcomes for silent fluency reading. These norms were compiled in the 1960's and therefore we have the standpoint that the norms should be much higher, taking into account the staggering increase in knowledge across the globe. Students have to study, interpret, assimilate and use much more information today than ever before in the history of mankind. Therefore, they should be able to read faster and remember more.

Figures 3, 4 and 5 refers to the pre- and post-evaluations done on both the Visagraph and the Lab-on-line system. Evaluations indicate outstanding improvements on all the following important aspects of the reading skill: optic-motor, perceptual and cognitive areas.

Most reading strategies focus largely on primary school learners, but we should also recognise that learning, especially the development of reading skills and strategies, should be a life-long practice that continues into high school and beyond. LAB-on-line results has proven reading skills development is possible even at FET (Further Education and Training) and Tertiary levels.

Reading development is therefore not completed at the end of Grade 3 or even at the end of Primary School years. As a skill needed for life-long learning, training in reading is important in developing the full potential of all nations. Lerner noticed (1971): "In fact, reading skills are never completely perfected; even into college and adult life one is 
still developing advanced reading skills. The development of more advanced comprehension skills, the attainment of study skills, an increase in reading rate, and the achievement of flexibility in reading for different purposes are the responsibility of secondary schools. It is at this point, when longer periods of concentrated reading are required, that many children begin to fail in reading!'[28]

LAB-on-line was used successfully as a reading recovery and reading skills development program for students from Grade 1 through Grade 12.

Successful improvement of skills has been proved through this monitored on-line system with best practise through a blended learning approach - specifically for ESL students.

\section{Feedback from students}

Students are aware of the benefits within completion of the first few lessons. Their responses were given at completion of the course in order to establish their experience of the on-line system.

Student 1: "After completing the first three lessons, I honestly could not understand how the LAB-on-line programme was going to assist me in improving my reading speed and comprehension. I thought it was a waste of my time but after completing my 12th lesson, the impact of the programme on my reading speed started to show. I am able to read faster and get a better understanding of everything I read."

Student 2: "Thank you very much for this opportunity. My reading ability has improved tremendously. I appreciate the work that you do. The reading program is the very best opportunity I ever had in my entire life because it has played a huge role on improving my reading speed, memory, vocabulary and the ability to read and understand a given text (from $50 \%$ to $100 \%$ )."

\section{Feedback from teachers and facilitators}

Positive feedback from Teachers and facilitators have been received on the assistance and support received through the Lab-on-line System. Teachers know they are not adequately equipped to improve reading skills in the classroom. Lab-on-line efficiently support and develop these teachers through yearly training and the on-line monitoring and support of a well-researched student management and reporting system. Lab-on-line enables teachers to develop and support their students with minimal time input yielding maximum results in a short time. Improvement of reading skills can and should be part of the curriculum from Grade 1 through to tertiary level and even beyond in the continued human resource development of South Africa. Every phase of life, every new employment opportunity has its own challenges.

Koenig et al. confirms that "Reading skills has been indicated to be crucial for academic success and should not be the cause for students to "drop out of college". This study revealed that the participating first-year students read at alarmingly low levels, which correlates with national and international concerns." [29] This study also indicates "By registering a student for an academic programme, the university implies that the modules offered will be within the grasp of the student. Therefore, the implication is that the institution should make an additional effort to support students that have backlogs to overcome the challenges they face in terms of academic success. It is reasonably expected that within four years the university will yield a student who is fully equipped with the necessary skills and knowledge to survive in the corporate world, but statistics on through-put and pass rates sadly do not reflect this commitment."'[30]

\section{Conclusions}

We can without doubt confirm that the significance of good reading skills for academic success can no longer be ignored. Koenig et al. advise that development programmes such as the reading programme should be compulsory for all first-year students in all faculties on their campus.[31] Furthermore it is important that students across all learning levels have the opportunity to access the best assistance and development for their reading and comprehension skills.

The LAB-on-line system can be used to develop reading and comprehension skills as well as intervene to assist students successfully to develop crucial academic skills through on-line participation.

The Student management and monitoring Platform ensures timely and accurate assistance. The results in improvement of reading skills in every level, that was confirmed through this study shows reading as a skill can and should be developed even into High School and Tertiary levels.

\section{Acknowledgements}

Thomas Marshall: Director LectorSA 
Addendum A

\begin{tabular}{|c|c|c|c|c|c|c|c|c|c|c|c|c|c|c|c|c|c|c|}
\hline & \multicolumn{2}{|c|}{ GRADE } & \multicolumn{10}{|c|}{ GRADE } & \multicolumn{2}{|c|}{$\begin{array}{l}1 e+ \\
2 e \\
j r\end{array}$} & \multirow{2}{*}{$\begin{array}{l}\mathrm{e} \\
\mathrm{jr} \\
1\end{array}$} & \multicolumn{3}{|c|}{ ADVANCED } \\
\hline & 1 & 2 & 3 & 4 & 5 & 6 & 7 & 8 & 9 & 10 & 11 & 12 & & & & 2 & 3 & 4 \\
\hline $\begin{array}{l}\text { Fixations } \\
\text { Per } \\
100 \mathrm{w}\end{array}$ & 224 & 174 & 155 & 139 & 129 & 120 & 114 & 109 & 105 & 101 & 96 & 94 & 90 & 77 & 65 & 57 & 48 & 44 \\
\hline $\begin{array}{l}\text { Regres- } \\
\text { sions } \\
\text { per } \\
100 \mathrm{w}\end{array}$ & 52 & 40 & 35 & 31 & 28 & 25 & 23 & 21 & 20 & 19 & 18 & 17 & 15 & 11 & 8 & 5 & 4 & 2 \\
\hline $\begin{array}{l}\text { Av spa of } \\
\text { Recog- } \\
\text { nition }\end{array}$ & .45 & .57 & .65 & .72 & .78 & .83 & .88 & .92 & .95 & .99 & 1.04 & 1.06 & 1.11 & 1.30 & 1.53 & 1.75 & 2.08 & 2.27 \\
\hline $\begin{array}{l}\text { Av } \\
\text { Duration } \\
\text { Of } \\
\text { Fixation }\end{array}$ & .33 & .30 & .28 & .27 & .27 & .27 & .27 & .27 & .27 & .26 & .26 & .25 & .24 & .23 & .22 & .22 & .22 & .22 \\
\hline $\begin{array}{l}\text { Words } \\
\text { Per } \\
\text { minute }\end{array}$ & 80 & 115 & 138 & 158 & 173 & 185 & 195 & 204 & 214 & 224 & 240 & 250 & 280 & 340 & 400 & 480 & 560 & 620 \\
\hline
\end{tabular}

Figure 2. Expected norms and standards

Addendum B

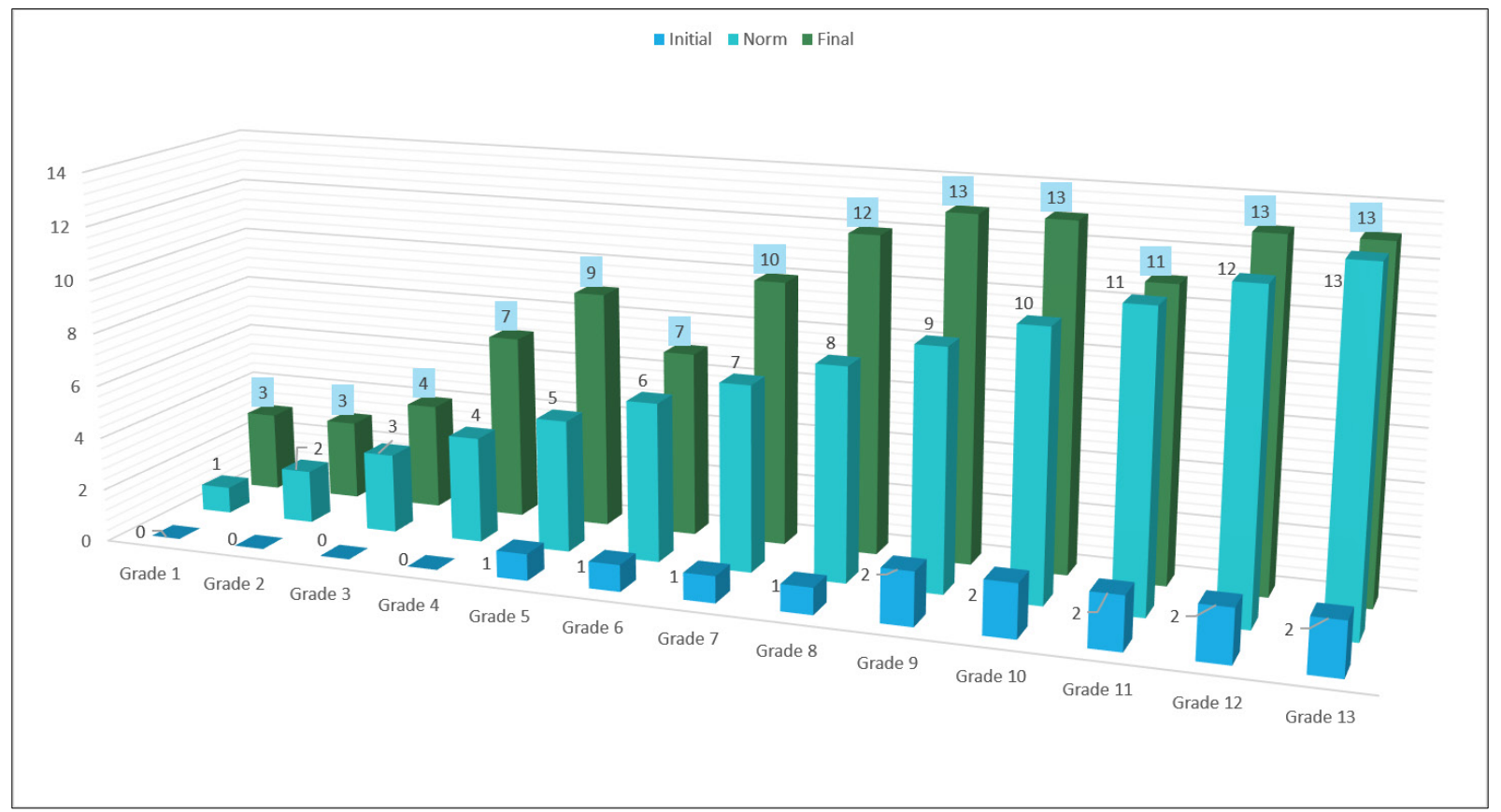

Figure 5. Final results of students on LAB-on-line 2014 


\section{REFERENCES}

[1] LectorSA internal research. http://lectorsa.com/assets/docs/L $\mathrm{AB} \%$ 20Success\%202015.pdf? $\mathrm{v}=\mathrm{Q} 4 \mathrm{tU}$ 51WfCEU

[2] LectorSA internal research. http://lectorsa.com/assets/docs/L $\mathrm{AB} \%$ 20Success\%202015.pdf? $\mathrm{v}=\mathrm{Q} 4 \mathrm{tU}$ 51WfCEU

[3] Twinton A 2007. Common Reading Programs in Higher Education. Gustavus Education. Retrieved 4 17, 2012. http://gustavus.edu//library/Pubs/Lindell207.html.

[4] http://www.educationgov.za/Portals/0/DoE\%20Branches/GE T/GET\%20Schools/National_Reading.pdf?ver=2009-09-09110716-507

[5] Retrieved 25 February 2016 http://www.scielo.org.za/scielo. php?script=sci_arttext\&pid=S0256-01002012000200007

[6] Howie S, Venter E, Van Staden S, Zimmerman L, Long C, Du Toit C, Scherman V \& Archer E 2006.Progress in International Reading Literacy Study 2006. University of Pretoria: Centre for Evaluation and Assessment.

[7] Pretorius EJ 2002. Reading ability and academic performance in South Africa: Are we fiddling while Rome is burning? Language Matters, 33:169-196.

[8] Louden, W., Chan, L., Elkins, J., Greaves, D., House, H. \& Milton, M. 2000. Mapping the territory. Canberra, Australia: Commonwealth Department of Education, Training and Youth Affairs.

[9] http://krepublishers.com/02-Journals/IJES/IJES-10-0-000-15 -Web/IJES-10-2-000-15-Abst-PDF/IJES-10-2-000-15-AbstPDF/IJES-10-2-297-15-445-Koenig-L/IJES-10-2-297-15-44 5-Koenig-L-Tx[12].pdf

[10] LAB-on-line was created by LectorSA http://lectorsa.com/our-story.html

[11] http://www.education.gov.za/Curriculum/AnnualNationalAs sessments(ANA).aspx

[12] retrieved 25 February 2016 http://www.scielo.org.za/scielo.p hp?script $=$ sci arttext\&pid $=$ S0256-01002012000200007

[13] http://lectorsa.com/index.html andhttp://www.ecoltech.co.za /

[14] Interview with Dr Sally E. Shaywitz, professor of pedeatric Neurology at Yale University http://www.childrenofthecode. org/interviews/shaywitz.htm\#BrainNotWired

[15] http://www.education.gov.za/Examinations/AnnualNational AssessmentsANA/tabid/569/Default.aspx
[16] Hacquebord H 1994. Academic literacy reading in the content areas: text comprehension in secondary education in the Netherlands. Journal of Research in Reading, 17: 83-98.

[17] Elley WB 1991. Acquiring literacy in a second language: the effect of book-based programmes. Language Learning, 41:375-411.

[18] Mbise A 1993. Teaching English language reading in Tanzanian secondary schools. In CM Rubagumya (ed). Teaching and researching language in African classrooms. Clevedon: Multilingual Matters, 96-109.

[19] https://www.nichd.nih.gov/publications/pubs/nrp/Documents /report.pdf

[20] http://lab-on-line.com/

[21] http://www.lectorsa.com/assets/docs/Student $\% 20$ briefing $\% 2$ 02015.pdf? $\mathrm{v}=\mathrm{Q} 4 \mathrm{tU}$ 1WfCEU

[22] http://lab-on-line.com/

[23] Terminology:Fixation = eye stop Regression = back movement of eye, ASR = Average span of recognition, $\mathrm{ADF}$ $=$ Average duration of fixation, $\mathrm{CC}=$ Cross Correlation differences between left and right eye, OEF = One eye forward, OER $=$ One eye backwards, $\mathrm{BEO}=$ Both eyes opposite direction, WPM = Reading speed expressed as words per minute, $\%=$ Comprehension outcome, $\mathrm{GLE}=$ Grade Level Efficiency (Optic-motor), Grade = Outcomes referenced against Grade level

[24] LAB-on-line Statistics. http://ecoltech.co.za/results.html

[25] LAB-on-line Statistics. http://ecoltech.co.za/results.html

[26] LectorSA Statistics. http://ecoltech.co.za/results.html

[27] National Reading strategy http://www.education.gov.za/Link Click.aspx?fileticket $=$ wj YeFLi8NC0\%3D\&tabid $=454 \& \mathrm{mid}$ $=401$

[28] Lerner, J. W. (1993). Learning disabilities: Theories, diagnosis, and teaching strategies. Dallas, TX: Houghton Mifflin.

[29] http://krepublishers.com/02-Journals/IJES/IJES-10-0-000-15 -Web/IJES-10-2-000-15-Abst-PDF/IJES-10-2-000-15-AbstPDF/IJES-10-2-297-15-445-Koenig-L/IJES-10-2-297-15-44 5-Koenig-L-Tx[12].pdf

[30] http://krepublishers.com/02-Journals/IJES/IJES-10-0-000-15 -Web/IJES-10-2-000-15-Abst-PDF/IJES-10-2-000-15-AbstPDF/IJES-10-2-297-15-445-Koenig-L/IJES-10-2-297-15-44 5-Koenig-L-Tx[12].pdf

[31] http://krepublishers.com/02-Journals/IJES/IJES-10-0-000-15 -Web/IJES-10-2-000-15-Abst-PDF/IJES-10-2-000-15-AbstPDF/IJES-10-2-297-15-445-Koenig-L/IJES-10-2-297-15-44 5-Koenig-L-Tx[12].pd 